\title{
Size of Gas Exchange Vessels in the Lung *
}

\author{
Marvin A. Sackner, $\dagger$ Khalil A. Feisal, and Daniel N. Karsch \\ (From the Department of Physiology, Graduate School of Medicine, University of \\ Pennsylvania, Philadelphia, Pa.)
}

The provocative experiments of Staub (1) on the color of blood in arterioles of rapidly frozen lungs prompted us to investigate the quantitative aspects of gas exchange in vessels larger than capillaries in a living animal. His study raised the question of whether the amount of precapillary gas exchange is sufficient to invalidate the physiologic measurement of $a$ ) intrapulmonary right to left shunt while breathing oxygen $(2), b)$ pulsatility of pulmonary capillary blood flow (3), and $c$ ) pulmonary arterial blood volume (4). We shall show both by measurements utilizing the ether plethysmographic method $(4,5)$ in a living dog and by calculations of the diffusing capacity of the pulmonary arterial system in a mathematical model that precapillary gas exchange is insufficient to invalidate the aforementioned techniques.

\section{Methods}

Theory. The injection of ether dissolved in alcohol into the pulmonary artery of an apneic dog enclosed within a body plethysmograph produces a rise in plethysmographic pressure. This is due to the dissolved ether in the blood becoming gaseous in the alveoli and signals the arrival of ether at the site where the major portion of gas exchange takes place. If ether is dissolved in Lipomul, 1 a fine emulsion of cottonseed oil in water, ether evolution in the lungs is not delayed because the particles of the emulsion are so small that they pass through the pulmonary capillaries (4). However, if ether is dissolved in kerosene, the rate of ether gas evolution from the kerosene is retarded, presumably because kerosene lodges in a pulmonary vessel that limits the diffusion of ether (5). The rapid injection of one liquid into another liquid with which it is immiscible produces droplets whose size is related to the velocity of injection and the kinematic viscosities of the liquids (6). The size of the kerosene droplets containing the ether can be estimated micro-

* Submitted for publication January 30, 1964 ; accepted June 4, 1964.

Supported in part by grant HE 4797 from the U. S. Public Health Service.

† American College of Physicians research fellow.

Present address: Cardiopulmonary Laboratory, Mt. Sinai Hospital, Miami Beach, Fla.

1 Upjohn Co., Kalamazoo, Mich. scopically. The rapid injection of a solution of ether in kerosene or ether dissolved in any other oil into the blood stream produces spherical droplets; those droplets less than $200 \mu$ in diameter are not deformed by the flowing stream (7). The droplets will be arrested by vessels equal to their diameter, and ether will diffuse from the droplets through the vessel wall into the alveoli. The droplets may undergo deformation and breakup, but extrapolating from measurements of the time necessary for breakup of large liquid bubbles entering a constriction of a tube (8), this probably would not be a significant factor during the time needed to generate an ether curve.

Pulmonary arterial circulation time. Eighteen mongrel dogs weighing 14 to $21 \mathrm{~kg}$ were used in these experiments. The dogs were anesthetized with sodium pentobarbital, $25 \mathrm{mg}$ per $\mathrm{kg}$, intravenously. A 7F Cournand catheter ${ }^{2}$ was introduced into the external jugular vein and passed into the pulmonary artery under fluoroscopic guidance in all of the dogs. In three dogs, additional 7F cardiac catheters were passed into the pulmonary artery and into the left ventricle from the internal carotid artery. In three other dogs, an $8 \mathrm{~F}$ double lumen balloon catheter was passed into the pulmonary artery. Each animal was enclosed within a horizontal Plexiglas body plethysmograph (4), paralyzed with succinylcholine, and ventilated with a Starling pump. Intravascular pressures were measured by strain gauges, ${ }^{3}$ and plethysmographic pressure was measured by a differential strain gauge 4 connected to a direct writing recorder. ${ }^{5}$

The plethysmograph was calibrated by injection and withdrawal of $10 \mathrm{ml}$ of air with a syringe such that a deflection of $25 \mathrm{~mm}$ was obtained on the record. After calibration, $0.5 \mathrm{ml}$ of a $1: 4$ ether in alcohol solution was instilled into the $7 F$ Cournand catheter. The respiratory pump was stopped, its tubes clamped, and the ether solution flushed into the pulmonary artery with $5 \mathrm{ml}$ saline delivered by a pressure injector ${ }^{6}$ at preset velocities of 760,910 , and $1,340 \mathrm{~cm}$ per second. After a few minutes, the injection was repeated. Duplicate injections were repeated until they showed a median transit time for ether evolution within 0.10 second of each other. The $7 \mathrm{~F}$ Cournand catheter was then filled with $0.5 \mathrm{ml}$ of ether 1:4 in an oil solution and this injected in the same

\footnotetext{
2 U. S. Catheter Corp., Glen Falls, N. Y.

3 Statham model P23 D, Puerto Rico.

4 Statham model PM 97TC \pm 0.05 to $350 \pm 0.05$ PSID, Puerto Rico.

5 Polygraph 5, Grass Instrument Co., Quincy, Mass.

6 Amplatz injector, Nedmac Inc., Minneapolis, Minn.
} 
way as the preceding ether in alcohol runs. The oil vehicles included kerosene, olive oil, and crude emulsions with $1 \%$ of Tween 20 of $50 \%$ kerosene in water and $70 \%$ olive oil in water. Three dogs were injected with ether dissolved in alcohol or oil after temporary occlusion of the left pulmonary artery with a balloon catheter.

Determination of droplet size in vitro. To simulate the pulmonary artery of a dog, fluid was circulated within a soft rubber tube with an i.d. of $1 \mathrm{~cm}$ at $50 \mathrm{~cm}$ per second by a peristaltic pump. The tip of a $7 \mathrm{~F}$ Cournand catheter ${ }^{2}$ was placed in the stream, the catheter filled with ether diluted $1: 4$ in the various oil vehicles employed in the animal experiments, and the ether-containing vehicles flushed into the stream by $5 \mathrm{ml}$ saline from a pressure injector $^{6}$ at velocities of 760,910 , and $1,340 \mathrm{~cm}$ per second. Citrated human blood was used as the circulating fluid in the initial experiments, but it was abandoned because the smaller droplets were confused with blood cells during microscopic estimation of droplet size. A $31 \%$ sucrose solution with $1 \%$ Tween 20 was substituted for blood. This solution had a kinematic viscosity of 2.90 centistokes at $25^{\circ} \mathrm{C.}{ }^{7}$

Within a second after injection of the ether in oil from the catheter into the circulating sucrose solution, a tap located $20 \mathrm{~cm}$ from the tip of the catheter was opened

${ }^{7}$ Cannon-Fenske-Ostwald type viscometer, A. $\mathrm{H}$. Thomas Co., Philadelphia, $\mathrm{Pa}$. and 25 to $50 \mathrm{ml}$ of fluid collected. A sample was immediately diluted with distilled water $1: 4$ to $1: 10$ and a sample from this dilution placed in a counting chamber 8 $0.2 \mathrm{~mm}$ deep within 30 seconds. The droplet diameter was estimated microscopically with the aid of a micrometer disc inserted in the eyepiece. Approximately 1,000 droplets were counted, and samples were done in duplicate.

Determination of droplet size in vivo. In six dogs, immediately after recording the rate of evolution of ether from an oil vehicle, a concentrated solution of potassium chloride was injected into the pulmonary artery or left ventricle. This produced cardiac arrest within 7 seconds. The chest was opened, and sections were taken from at least three areas of each lung. The lung tissue was fixed in formalin, stained with Sudan red, counterstained with hematoxylin and eosin, and the frozen sections cut in 75- $\mu$ thicknesses. Approximately 5,000 droplets were counted for each dog's lungs.

\section{Results}

A diagram of an experiment is shown in Figure 1. The first rise of plethysmographic pressure is caused by the $5 \mathrm{ml}$ saline that flushes out the catheter, and the next rise reflects the entry of

8 Speir's-Levy eosinophil counter, A. H. Thomas Co., Philadelphia, $\mathrm{Pa}$.

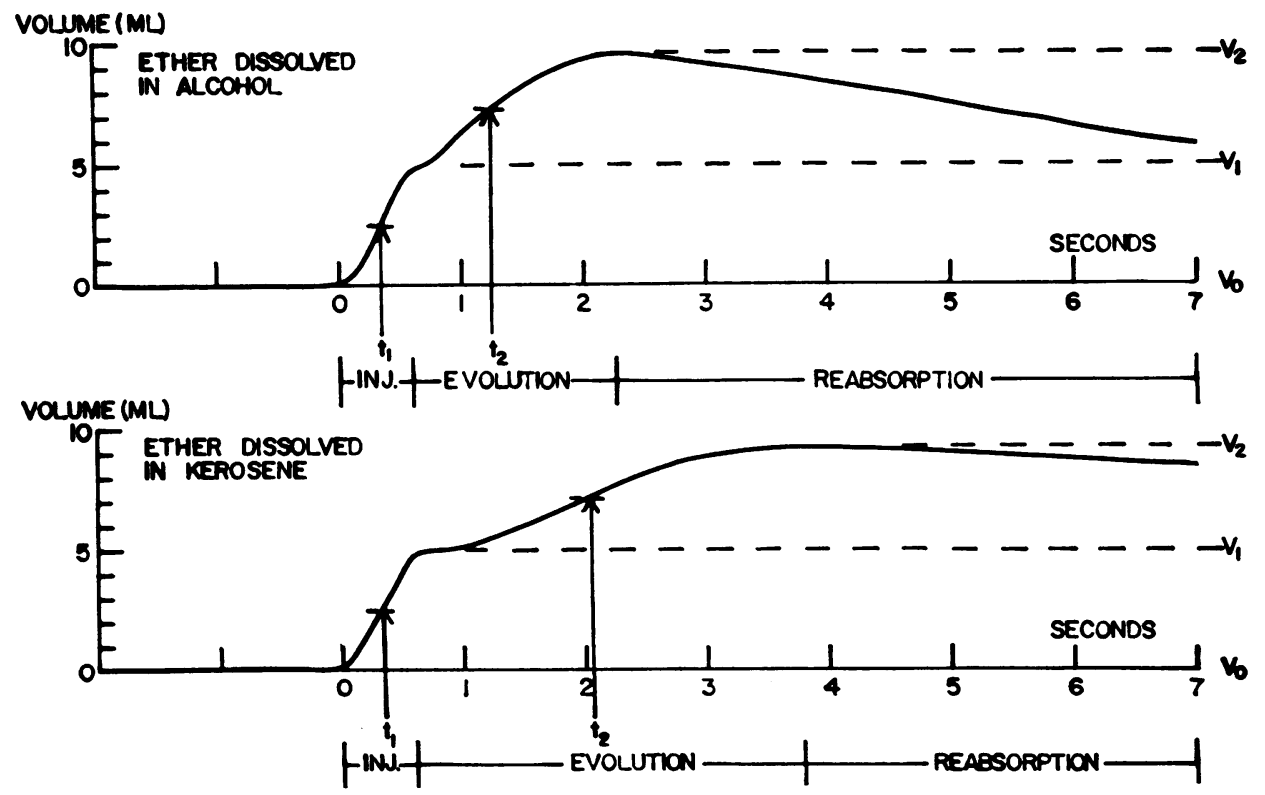

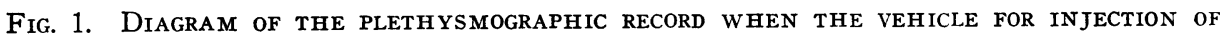
ETHER IS ALCOHOL OR KEROSENE. The rise in volume from $V_{0}$ to $V_{1}$ is due to the injection of $5 \mathrm{ml}$ saline to flush the ether solution from the catheter. The rise in volume between $V_{1}$ and $\mathrm{V}_{2}$ is due to evolution of dissolved ether from the pulmonary blood to gas in the alveoli. The fall in volume between $V_{2}$ and $V_{1}$ is due to reabsorption of ether gas in the alveoli by ether-free pulmonary blood entering the pulmonary vessels. The median transit time is the time between the mid-volume point of injection $\left(t_{1}\right)$ and the mid-volume point of ether evolution $\left(t_{2}\right)$ and represents the time for half the ether to arrive at the site of gas exchange. The median transit time is prolonged when kerosene is used as a vehicle. 
TABLE I

Evolution of ether gas from alcohol and oil vehicles

\begin{tabular}{|c|c|c|c|c|c|c|}
\hline Experiment & Dog & $\begin{array}{c}\text { Velocity of } \\
\text { injection }\end{array}$ & $\begin{array}{c}\text { Ether in } \\
\text { alcohol, } \\
\text { median } \\
\text { transit } \\
\text { time }\end{array}$ & Vehicle* & $\begin{array}{c}\text { Ether in } \\
\text { vehicle, } \\
\text { median } \\
\text { transit } \\
\text { time }\end{array}$ & $\begin{array}{c}\text { Delay in } \\
\text { median } \\
\text { transit } \\
\text { time }\end{array}$ \\
\hline & & $\mathrm{cm} / \mathrm{sec}$ & sec & & sec & sec \\
\hline 1 & 1 & 760 & 1.02 & $\mathrm{~K}$ & 1.86 & 0.84 \\
\hline 2 & 2 & 760 & 0.68 & $\mathrm{~K}$ & 1.04 & 0.36 \\
\hline 3 & 2 & 760 & 0.72 & $\mathrm{~K}$ & 1.20 & 0.48 \\
\hline 4 & 15 & 760 & 0.90 & $\mathrm{~K}$ & 1.20 & 0.30 \\
\hline 5 & 5 & 760 & 1.00 & $\mathrm{O}$ & 1.30 & 0.30 \\
\hline 6 & 10 & 760 & 0.53 & $\mathrm{O}$ & 0.72 & 0.19 \\
\hline 7 & 3 & 910 & 0.67 & $\mathrm{~K}$ & 0.84 & 0.17 \\
\hline 8 & 9 & 910 & 1.02 & $\mathrm{~K}$ & 1.48 & 0.46 \\
\hline 9 & 14 & 910 & 0.65 & $\mathrm{~K}$ & 1.64 & 0.99 \\
\hline 10 & 14 & 910 & 0.94 & $\mathrm{~K}$ & 1.52 & 0.58 \\
\hline 11 & 4 & 1,340 & 0.63 & $\mathrm{~K}$ & 1.50 & 0.87 \\
\hline 12 & 11 & 1,340 & 0.37 & $\mathrm{~K}$ & 1.12 & 0.75 \\
\hline 13 & 12 & 1,340 & 0.90 & $\mathrm{O}$ & 1.16 & 0.26 \\
\hline 14 & 7 & 760 & 0.40 & $\mathrm{OE}$ & 0.36 & \\
\hline 15 & 7 & 760 & 0.47 & $\mathrm{OE}$ & 0.44 & \\
\hline 16 & 8 & 760 & 0.44 & $\mathrm{OE}$ & 0.38 & \\
\hline 17 & 13 & 760 & 0.40 & OE & 0.36 & \\
\hline 18 & 6 & 760 & 0.75 & $\mathrm{KE}$ & 0.64 & \\
\hline 19 & 6 & 760 & 0.74 & $\mathrm{KE}$ & 0.76 & \\
\hline 20 & 6 & 760 & 0.83 & $\mathrm{KE}$ & 0.84 & \\
\hline
\end{tabular}

${ }^{*} \mathrm{~K}=$ kerosene $; \mathrm{O}=$ olive oil $; \mathrm{OE}=70 \%$ olive oil in water emulsion; $\mathrm{KE}=50 \%$ kerosene in water emulsion.

ether gas into the alveoli. The median transit time is the interval between the time at which the injection artifact reaches half its maximal value and the time at which the rise of plethysmographic pressure caused by appearance of ether in the alveoli reaches half its peak value (4). Table I lists the results of comparisons in median transit times between ether in alcohol and ether in oil. In all 13 experiments with ether in kerosene or olive oil, there was a significant delay in the evolution of ether. The median transit time was prolonged a mean of 0.50 second (range, 0.17 to 0.99

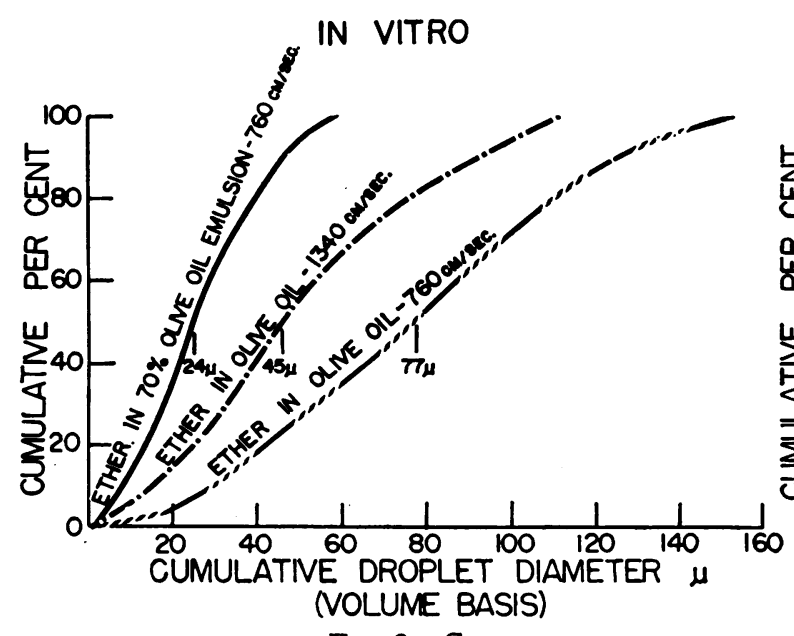

Fig. 2. Cumulative frequency curves of Droplet distribution. second). In all four experiments with ether in the emulsion of $70 \%$ olive oil in water and in all three trials with ether in the emulsion of $50 \%$ kerosene in water, there was no significant delay in the evolution of ether gas compared to that from ether dissolved in alcohol.

Cumulative frequency curves of droplet distribution for both in vitro and in vivo experiments with olive oil are shown in Figure 2. In vivo data for the kerosene vehicles were not obtained because of inability to stain the kerosene. In Table II are summarized the median droplet diameters for

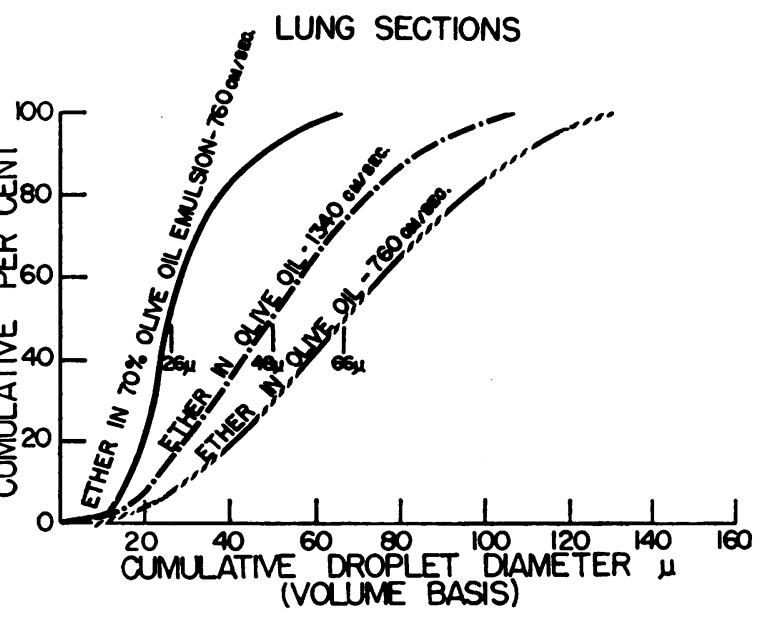


TABLE II

Droplet size for ether in oil vehicles

\begin{tabular}{|c|c|c|c|c|}
\hline Vehicle & $\begin{array}{l}\text { Injection } \\
\text { velocity }\end{array}$ & $\begin{array}{c}\text { Median } \\
\text { droplet } \\
\text { diameter }\end{array}$ & $\begin{array}{c}10 \text { to } 90 \\
\text { percentile } \\
\text { diameter }\end{array}$ & $\begin{array}{l}\text { No. } \\
\text { droplets } \\
\text { counted }\end{array}$ \\
\hline \multicolumn{5}{|c|}{$\mathrm{cm} / \mathrm{sec}$} \\
\hline & & In vitro & & \\
\hline Kerosene & 760 & 68 & $34-106$ & 1,600 \\
\hline Kerosene & 910 & 57 & $28-93$ & 2,178 \\
\hline Kerosene & 1,340 & 44 & $9-60$ & 2,984 \\
\hline Olive oil & 760 & 77 & $30-128$ & 2,145 \\
\hline Olive oil & 910 & 48 & $22-102$ & 2,169 \\
\hline Olive oil & 1,340 & 45 & $19-94$ & 2,465 \\
\hline $\begin{array}{l}70 \% \text { Olive oil in } \\
\text { water emulsion }\end{array}$ & 760 & 24 & 9-45 & 4,407 \\
\hline $50 \%$ Kerosene in & & & & \\
\hline water emulsion & 760 & 10 & $4-31$ & 2,167 \\
\hline Lipomul & 760 & $<1$ & $<1$ & 2,090 \\
\hline \multicolumn{5}{|c|}{ Lung sections } \\
\hline Olive oil & 760 & 66 & $28-106$ & 5,525 \\
\hline Olive oil & 1,340 & 48 & $23-88$ & 5,197 \\
\hline $\begin{array}{l}70 \% \text { Olive oil in } \\
\text { water emulsion }\end{array}$ & 760 & 26 & $16-46$ & 5,192 \\
\hline
\end{tabular}

all the experiments. The smallest median droplet diameter in vitro for the kerosene and olive oil vehicles was $44 \mu$; the largest median droplet diameter in vitro for the emulsions was $24 \mu$. Droplet diameters in lung sections were approximately equal to those obtained in the hydrodynamic model.

The injections of ether in oil in the present experiments did not affect the pulmonary arterial pressure, the left ventricular pressure, or pulse rate.

Temporary unilateral pulmonary arterial occlusion with a balloon catheter performed six times in three dogs decreased the median transit time for ether in alcohol a mean of $34 \%, \mathrm{SD} 4 \%$. In two experiments, the delay of ether evolution from kerosene was similar before and during unilateral pulmonary arterial occlusion.

\section{Discussion}

Site of impaction of oil droplets. The present experiments show that there is a limitation to exchange of a highly soluble gas, ethyl ether, between the blood and alveoli when the gas is dissolved in oil droplets greater than $44 \mu$ in diameter but not when the gas is dissolved in droplets less than 24 $\mu$ in diameter. However, the true size of the vessel occluded by the droplet depends upon other factors in addition to the droplet diameter. When a droplet reaches a pulmonary arteriole whose diameter is equal to its own, blood flow in that vessel approaches a standstill, and arteriolar pres- sure rises to arterial pressure. The magnitude of the rise may be as much as $25 \%$ of arteriolar pressure (9). Assuming a compliance of $6.5 \times 10^{-9}$ $\mathrm{ml}$ per $\mathrm{cm} \mathrm{H}_{2} \mathrm{O}$ and a blood volume of $1.23 \times 10^{-8}$ $\mathrm{ml}$ for a pulmonary arteriole $30 \mu$ in diameter (10) and a change in pressure of $4 \mathrm{~cm} \mathrm{H}_{2} \mathrm{O}$, one can calculate that arteriolar diameter might increase $6 \%$ after impaction of the droplet. After impaction, the droplet may deform from a spherical to an elliptical shape, but studies of the lung sections indicate that most droplets are spherical or only slightly deformed. In addition to the preceding, artifacts in the counting procedure also must be considered. All techniques of microscopic estimation of droplet size tend to underestimate the number of smaller droplets. In the animal experiments, droplets whose diameter was the same or less than the pulmonary capillaries would have passed through the pulmonary vascular bed by the time the animal was killed. Large droplets that passed through arteriovenous anastomosis would not be counted, too, but evidence has been presented that this is of little consequence during the first circulation (11). In the final analysis, the true size of vessels occluded by the droplets might be smaller than the measured droplet diameters, and hence the latter should be considered an approximation only.

The rates of ether evolution from the injection of ether dissolved in the $70 \%$ olive oil in water emulsion and ether dissolved in alcohol were the same. This indicated that equilibration of ether between the alveoli, blood, and tissues might be complete at the site where the droplets of the emulsion had impacted. An alternative explanation that it might be the result of ether dissolved in the water phase of the emulsion diffusing from the capillaries does not seem tenable, since only $14 \%$ of the injected ether was dissolved in the water phase, and the volume of ether evolved was similar for ether in both alcohol and emulsion injections. An unknown quantity of ether will, however, diffuse from the oil droplets to the blood during transit from the injection to the impaction site. This cannot be readily calculated but is probably small, since droplets only $20 \mu$ in diameter larger than the emulsion droplets gave a significant delay in evolution of ether.

Physiologic significance of the rate of ether evolution from oil vehicles. The factors that 
might be responsible for the delay in evolution of ether gas through arterioles $44 \mu$ in diameter or larger include a delay in arrival of the droplets at the site of gas exchange, too few droplets delivered to the arteriolar lumen, and limitation of diffusion of ether from the oil vehicle through the vessel wall or through the alveoli. Delay in arrival of the droplets at the site of gas exchange might occur because of the droplets' flow resistance, which is a function of droplet size and the ratio of the droplet viscosity to the viscosity of blood. However, the similarity of results for both injections of ether in kerosene that had a kinematic viscosity of 1.39 centistokes at $25^{\circ} \mathrm{C}$, and ether in olive oil that had a kinematic viscosity of 16.48 centistokes at $25^{\circ} \mathrm{C}^{7}$ makes this factor unlikely. Further, the increase of velocity of pulmonary blood flow during unilateral pulmonary arterial occlusion did not alter the rate of ether evolution from oil.

Limitation to diffusion of ether from oil can be dismissed, for if there is no barrier to diffusion other than the oil itself, a droplet as large as $80 \mu$ in diameter would release $90 \%$ of its ether within 0.005 second (12). If a larger droplet is created from a standard volume of oil, there are fewer droplets delivered to the diffusing surface of the arterioles. When the injected volumes of ether dissolved in kerosene were varied from 0.3 to 2.0 $\mathrm{ml}$, however, the delay of ether gas evolution compared to ether dissolved in alcohol was retained. It is also unlikely that the alveolar distance between pulmonary arterioles is great enough to significantly delay the equilibration of ether between alveolar air and the pulmonary tissues, provided there is no other limitation to diffusion. Distance between pulmonary arterioles is unknown, but the pulmonary arterial branching pattern from the main pulmonary artery to vessels of $1,000 \mu$ in diameter has been shown to follow almost exactly the same pattern as the bronchial tree, and the vascular dimensions are nearly the same as the accompanying bronchi (13). If one assumes an intra-alveolar distance of $1,000 \mu$ between vessels of $1,000 \mu$ in diameter, the time required to reduce the alveolar concentration gradient of ether to $16 \%$ of its original value is 0.02 second, and for an intra-alveolar distance of $500 \mu$, only 0.005 second (14). Since the number of branchings of the pulmonary vessels far exceeds the airways (13), the shorter distance between the smaller arterioles would lead to an even shorter diffusion time. Thus, the vessel wall itself appears to be limiting the diffusion of ether from the vascular system. The experimental results indicate that the anatomic precapillaries, vessels about $24 \mu$ in diameter, permit normal exchange of ether gas. However, these data were obtained with the blood flow stopped, whereas the physiologic situation dictates a flowing stream. In the latter circumstance, the ether might not spend enough time in this vascular segment to allow equilibration of the ether between blood, air, and tissue. Therefore, a mathematical model was devised to aid in the interpretation of the experimental results.

Gaseous diffusion through the vessel wall. The diffusing capacity of the vessel wall can be calculated for steady-state conditions by the following equations (15).

$$
D_{\mathrm{w}}=\frac{2 \pi \cdot \mathrm{l} \cdot \mathrm{n} \cdot \mathrm{d} \cdot \lambda \cdot 60}{\left(\ln \mathrm{r}_{0}-\ln \mathrm{r}_{\mathrm{i}}\right) \cdot 760} \simeq \frac{\mathrm{A} \cdot \mathrm{d} \cdot \lambda \cdot 60}{\mathrm{~h} \cdot 760},
$$

where $D_{w}$ is diffusing capacity of wall in milliliters per minute $\times$ millimeter $\mathrm{Hg}, 1$ is length of vascular segment in centimeters, $n$ is number of vessels of particular segment in centimeters, $d$ is diffusion coefficient of gas in water in centimeters squared per second, $\lambda$ is solubility coefficient of gas in water in milliliters per milliliter water, $r_{0}$ is outer radius of vessel in centimeters, $r_{i}$ is inner radius of vessel in centimeters, $A$ is surface area in centimeters squared, and $h$ is wall thickness in centimeters. The first expression is for diffusion through a cylinder, but for ease of calculation the second expression of diffusion through a membrane does not introduce a significant error.

With the lungs of a $7-\mathrm{kg}$ dog as a model, the number and length of the pulmonary arteries and arterioles can be approximated from the formulas of Engelberg and DuBois (10). For the calculation of inner and outer radii and wall thickness, the ratio of wall thickness to total diameter for vessels from 0.001 to $0.010 \mathrm{~cm}$ in diameter can be assumed to be 0.10 ; for vessels 0.010 to $0.10 \mathrm{~cm}$, 0.09 ; and for vessels 0.10 to $1.15 \mathrm{~cm}, 0.08$ (16, 17). For the pulmonary capillaries, the surface area can be approximated from the equation of Weibel and Gomez (13), assuming an alveolar volume of $120 \mathrm{ml}$ and pulmonary tissue plus capil- 


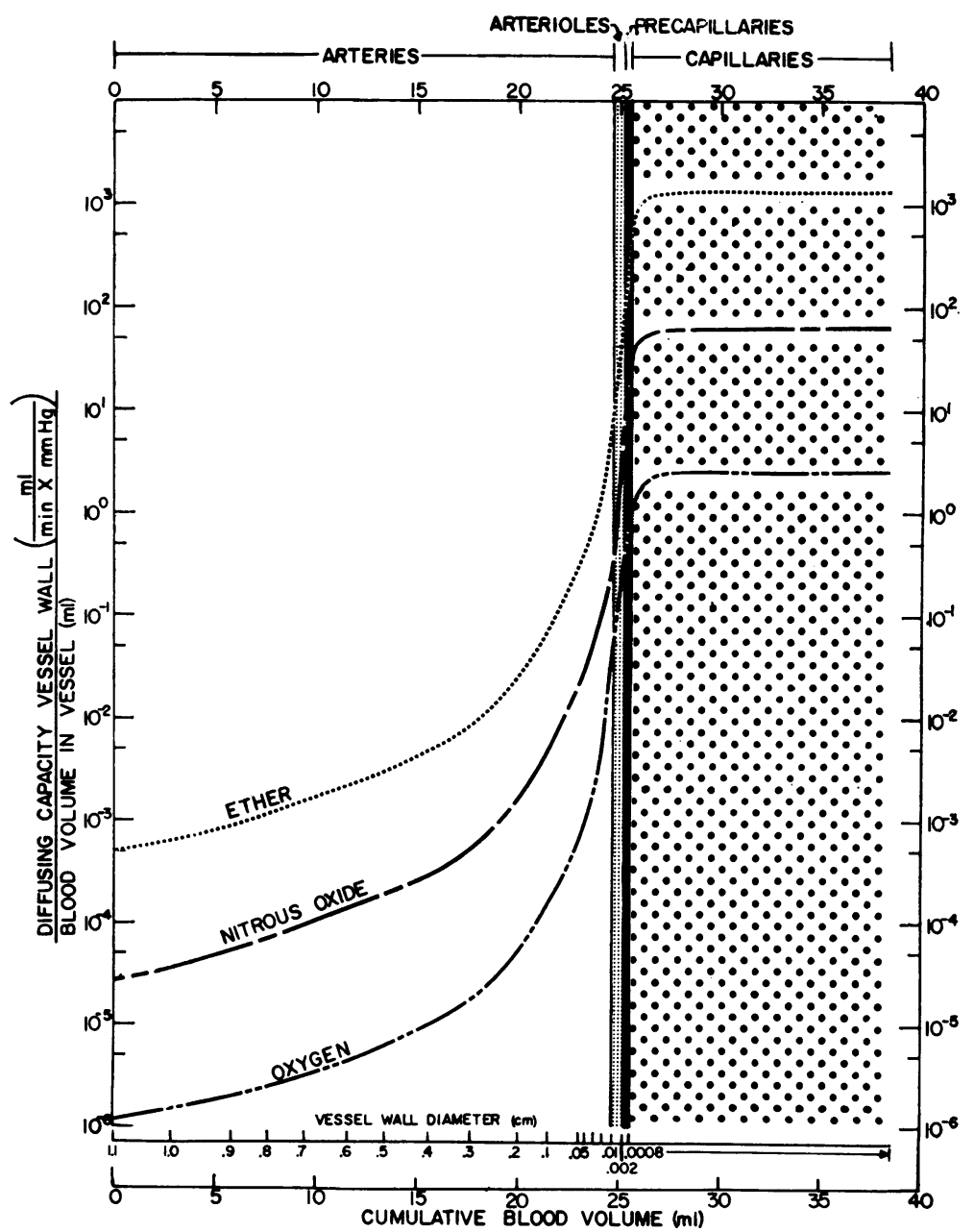

Fig. 3. ThEORETICAL DIFFUSING CAPACITY OF PULMONARY ARTERIAL WALLS AND CAPILlaries PLOTTED AS A FUNCTION OF CUMULATIVE BLOOD VOLUME AND VESSEL DIAMETER. Diffusing capacity is for BTPS conditions for both ether and $\mathrm{N}_{2} \mathrm{O}$ and STPD for oxygen. The differences among ether, nitrous oxide, and oxygen are related mainly to differences of solubility in water. Although the diffusing capacity rises rapidly for the arterioles and precapillaries, the volumes of these segments are small compared to the capillaries. Thus, blood is not in contact with the arterioles and precapillaries long enough to permit significant amounts of diffusion of gas from the blood to the alveoli and pulmonary tissues.

lary volume of $45 \mathrm{ml}$. The mean capillary wall thickness is $0.5 \mu$ (18). The diffusing coefficient of ether in water at $37^{\circ} \mathrm{C}$ is $1.25 \times 10^{-5} \mathrm{~cm}^{2}$ per second (19), and the solubility coefficient at $37^{\circ}$ is $15.5 \mathrm{ml}$ per $\mathrm{ml}$ water (20). In Table II, representative values for vascular dimensions and diffusing capacity of the vessel wall are listed. Figure 3 is a semilogarithmic plot of the diffusing capacity of the vessel wall against the vessel diameter and the cumulative blood volume. The semi- logarithmic scale was chosen for convenient display of the data. The graph shows that the rise in diffusing capacity is accelerated as the small arterioles are reached, but the vascular volumes of these segments are small, and blood is in contact with these segments for a short period compared to the capillaries represented by the upper plateau.

The time in seconds ether spends in a vascular segment equals the volume of segment in milliliters divided by the pulmonary blood flow in mil- 
liliters per second [2]. These times are listed in Table III for an assumed pulmonary blood flow of $20 \mathrm{ml}$ per second. The quantity of ether diffusing through the vascular wall is represented by the equation,

$$
\mathrm{dQ} / \mathrm{dt}=\left(\mathrm{PB}_{\mathrm{B}}-\mathrm{P}_{\mathrm{A}+\mathrm{T}+\mathrm{C}}\right) \cdot \mathrm{D}_{\mathrm{w}},
$$

where $\mathrm{dQ} / \mathrm{dt}$ is the volume of gas diffusing per unit time; $\mathrm{P}_{\mathbf{B}}$ the partial pressure of the gas in the blood; $\mathrm{P}_{\mathbf{A}+\mathbf{T}+\mathrm{C}}$ the partial pressure of gas, assumed to be equal in the alveoli, tissues, and capillaries; and $D_{w}$ the diffusing capacity of the vessel wall for the gas. The following equations may be substituted in Equation 3.

$$
\mathrm{PB}=\mathrm{PB}_{0}-\frac{\mathrm{Q}(\mathrm{B}-99)}{\lambda \mathrm{VB}},
$$

and

$$
\mathrm{P}_{\mathrm{A}+\mathrm{T}+\mathrm{C}}=\frac{\mathrm{Q}(\mathrm{B}-47)}{\lambda\left(\mathrm{V}_{\mathrm{T}+\mathrm{C}}\right)+\mathrm{V}_{\mathrm{A}}},
$$

where $\mathrm{PB}_{\mathbf{0}}$ is the partial pressure of the gas upon entering the vascular segment, $\mathrm{B}$ the barometric pressure, (B-99) the sum of partial pressures of gases in venous blood, (B-47) the pressure of alveolar gas, $\mathrm{VB}$ the volume of blood diluting the solution of injected gas, $V_{\mathbf{T}+\mathbf{C}}$ the volume of the pulmonary tissues and capillaries, and $V_{A}$ the volume of alveolar gas. Integration of Equation 3 leads to the following solution:

$$
\begin{aligned}
Q=\frac{P_{B_{0}}}{\frac{B-99}{\lambda V_{B}}+\frac{B-47}{\lambda\left(V_{T+C}\right)+V_{A}}} \\
\cdot l-e^{-D w\left(\frac{B-99}{\lambda V_{B}}+\frac{B-47}{\lambda\left(V_{T}+c\right)+V_{A}}\right) t} .
\end{aligned}
$$

At time zero, the injection of $0.1 \mathrm{ml}$ of liquid ether into the pulmonary artery is equivalent to the injection of $26 \mathrm{ml}$ of ether gas in solution (4). This solution mixes with the blood, the amount of blood in which it is diluted depending upon the rate of injection, the blood flow, and the velocity imparted to the injected ether. The initial mean partial pressure of ether in the blood might be $34 \mathrm{~mm} \mathrm{Hg}$. Substitution of this value and the values for the constants in Equation 4 leads to $Q=15.6\left(1-\mathrm{e}^{-2.18 \mathrm{Dwt}}\right)$. From this equation, we found that $9 \%$ of the injected ether equilibrates with $\mathrm{V}_{\mathbf{T}+\mathbf{C}+\mathbf{A}}$ in the mathematical model across vessels 8 to $20 \mu$ in diameter (vicinity of the anatomic precapillaries), $0.2 \%$ across the remainder

TABLE III

Diffusing capacity of pulmonary arterial walls and capillaries*

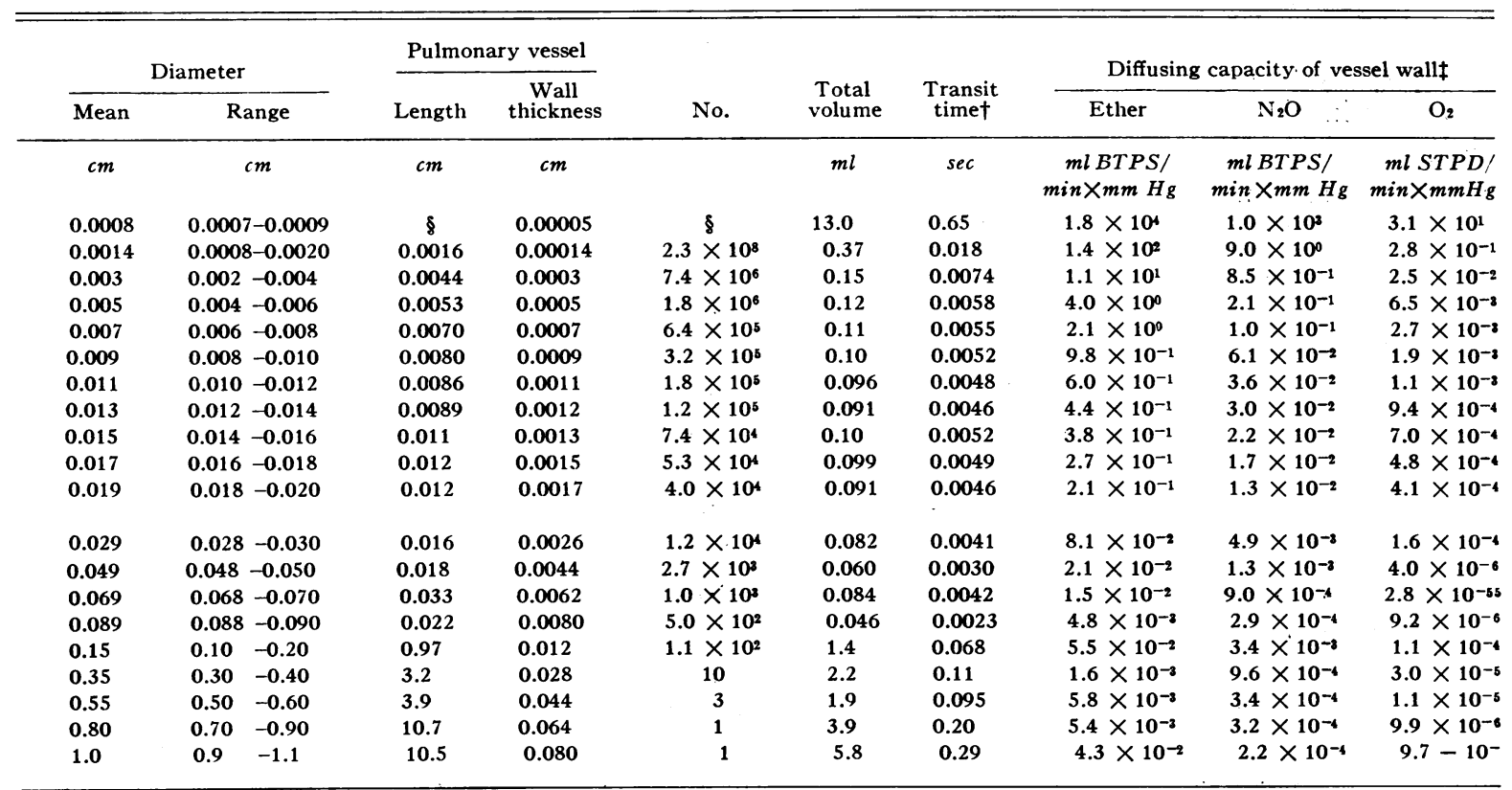

* Sequential values for vessels from 0.0008 to $0.019 \mathrm{~cm}$ in diameter; representative values for larger vessels.

+ With pulmonary blood flow of 1:2 L per minute.

BTPS = body temperature, pressure, saturated; STPD = standard temperature, pressure, dry.

BTPS = body temperature, pressure, saturated;
Assuming pulmonary capillary surface area of $6.7 \mathrm{~m}^{2}$. 
of the arterial system, and the rest across the first hundredth length of the anatomic capillaries. These results appear to conflict with the experimental findings that complete equilibration of ether takes place from vessels about $24 \mu$ in diameter. This discrepancy might be partly due to an overestimation of the size of the vessel occluded by the droplet. Further, calculations from the model were based upon a flowing stream in which blood flows from the precapillaries in $0.018 \mathrm{sec}$ ond (Table III), whereas in the injection experiments flow was stopped by the oil droplets, thus allowing a prolonged time for ether diffusion through the walls of vessels larger than capillaries. It is difficult to calculate the quantity of ether diffusing through the walls of vessels of the mathematical model during simulated cessation of flow in such vessels. In addition to the diffusing capacity of the vessel wall, other factors such as the arrival of ether at the vessel as a cumulative frequency function and the uptake of ether from the tissues and alveoli by pulmonary capillary blood flow must be considered. Some idea of the differences among the various sized vessels may be obtained by calculation according to Equation 4 of the time for half the ether evolution, assuming that the ether arrives as a square wave: capillaries ( $8 \mu$ in diameter), 0.001 second ; $14-\mu$ vessels, 0.12 second ; $30-\mu$ vessels, 1.7 seconds ; and $50-\mu$ vessels, 10 seconds.

During inspiration of a gas, all the pulmonary vessels are exposed simultaneously to the gas rather than sequentially as they would be after injections of ether solutions into the pulmonary artery. In the case of oxygen, the diffusing capacities of the walls of the pulmonary arterial system for oxygen (Table III, Figure 3 ) are so small that back pressure in the blood can be neglected. If we assume a partial pressure gradient for oxygen of $600 \mathrm{~mm} \mathrm{Hg}$ from alveoli to blood, calculations from the mathematical model for a $7-\mathrm{kg}$ dog indicate that only $0.1 \%$ of the $4.5 \mathrm{vol}$ per $100 \mathrm{ml}$ of oxygen added to the blood in the lungs is transferred in vessels from 8 to $20 \mu$ in diameter, and less than $0.003 \%$ in the rest of the pulmonary arterial system. This result does not conflict with observations in human subjects that before recirculation inspired hydrogen or oxygen is detected from the tip of a platinum electrode catheter, 2 to $4 \mathrm{~mm}$ in diameter, wedged into a pulmonary arterial branch. Since the platinum electrode was not calibrated during these experiments, the results were qualitative in nature (2123). Also, since the electrode is in contact with the arterial wall, the recording from the electrode probably reflects the gaseous tension in the arterial wall rather than the blood stream. In such a situation it can be calculated (12) that for an artery $2 \mathrm{~mm}$ in diameter the mean wall oxygen tension rises to $15 \%$ from its initial value toward alveolar oxygen tension during the 1 second required to register a curve from the electrode. Although diffusion of oxygen occurs at such sites, the diffusing capacity of the wall of these vessels is so small and the transit time for blood so rapid that negligible oxygen is transferred in terms of raising the oxygen saturation of the blood. It is more difficult to explain the semiquantitative results of Staub (1), who found that significant amounts of oxygen diffused across arterioles as large as $200 \mu$ in diameter while breathing oxygen. In our mathematical model with cessation of blood flow for the same period as Staub's experiments during the freezing of the lungs, there would not be sufficient transfer of oxygen across such vessels to turn the blood from blue to red. Since reflux of blood in the major pulmonary arterial branches normally takes place during diastole (24), reflux of oxygenated blood from the capillaries of the arterioles during the freezing procedure might contribute oxygenated blood to the arterioles.

\section{Summary}

The purpose of this study was to determine the size of vessels that permits the bulk of gas exchange in the lung. After injection of ether dissolved in alcohol into the pulmonary artery of an apneic dog enclosed within a body plethysmograph, pressure in the plethysmograph rises as ether arrives at the site of gas exchange. The time for ether evolution from ether dissolved in alcohol was compared to the time from ether dissolved in oil vehicles. The size of the oil droplet was measured both from in vitro experiments and from microscopic sections of the lung. The droplets are arrested in vessels whose diameter is equal to the droplet diameter. The time for ether evolution from droplets occluding vessels in the vicinity of the anatomic precapillaries is not meas- 
urably longer than the time required from injections of ether dissolved in alcohol. The time for ether evolution is delayed in larger vessels because rate of passage through the vessel wall is diffusion limited. Calculations from a mathematical model of the pulmonary arterial system of a 7-kg dog while the blood is flowing indicate that less than $0.2 \%$ of injected ether equilibrates across the arterial system before reaching vessels from 8 to $20 \mu$ in diameter (vicinity of anatomic precapillaries), $9 \%$ across the precapillaries, and the remainder across the first hundredth length of the anatomic capillaries. Other calculations indicate that during oxygen breathing less than $0.003 \%$ of the oxygen added to the blood diffuses from the alveoli into the arterial system before the anatomic capillaries, and only $0.1 \%$ diffuses into the blood while it is passing through the anatomic precapillaries.

\section{Acknowledgments}

The authors are deeply indebted to Dr. Arthur B. DuBois for his constructive criticism throughout the study and for his suggestion of the analysis of a mathematical model. The authors express their thanks to Mrs. Martha Keller for preparing the histologic sections and to Dr. Allan J. Steinberg for suggestions as to their interpretation. Dr. A. Sakamoto participated in some of the experiments.

\section{References}

1. Staub, N. C. Gas exchange vessels in the cat lung. Fed. Proc. 1961, 20, 107.

2. Staub, N. C. Microcirculation of the lung utilizing very rapid freezing. Angiology 1961, 12, 469.

3. Linderholm, H., P. Kimbel, D. H. Lewis, and A. B. DuBois. Pulmonary capillary blood flow during cardiac catheterization. J. appl. Physiol. 1962, 17, 135.

4. Feisal, K. A., J. Soni, and A. B. DuBois. Pulmonary arterial circulation time, pulmonary arterial blood volume, and the ratio of gas to tissue volume in the lungs of dogs. J. clin. Invest. 1962, 41, 390.

5. Feisal, K. A., M. A. Sackner, and A. B. DuBois. Comparison between the time available and the time required for $\mathrm{CO}_{2}$ equilibration in the lung. J. clin. Invest. 1963, 42, 24.

6. Richardson, E. G. The formation and flow of emulsion. J. Colloid Sci. 1950, 5, 404.

7. Bartok, W., and S. G. Mason. Particle motions in sheared suspensions. VIII. Singlets and doublets of fluid spheres. J. Colloid Sci. 1959, 14, 13.
8. Goldsmith, H. L., and S. G. Mason. The flow of suspensions through tubes. II. Single large bubbles. J. Colloid Sci. 1963, 18, 237.

9. Rappaport, M. B., E. H. Bloch, and J. W. Irwin. A manometer for measuring dynamic pressures in the microvascular system. J. appl. Physiol. 1959, 14, 651.

10. Engelberg, J., and A. B. DuBois. Mechanics of pulmonary circulation in isolated rabbit lungs. Amer. J. Physiol. 1959, 196, 401.

11. Ring, G. C., A. S. Blum, T. Kurbatov, W. G. Moss, and W. Smith. Size of microspheres passing through pulmonary circuit in the dog. Amer. J. Physiol. 1961, 200, 1191.

12. Hill, A. V. The diffusion of oxygen and lactic acid through tissues. Proc. roy. Soc. B 1928, 104, 39.

13. Weibel, E. R., and D. M. Gomez. Architecture of the human lung. Science 1962, 137, 577.

14. Rauwerda, P. E. Unequal Ventilation of Different Parts of the Lung and the Determination of Cardiac Output. Thesis, University of Groningen, 1946, pp. 65-67.

15. Jacobs, M. H. Diffusion processes. Ergebn. Biol. 1935, $12,1$.

16. Harris, P., and D. Heath. The Human Pulmonary Circulation. Baltimore, Williams \& Wilkins, 1962, pp. 14-18.

17. McDonald, D. A. Blood Flow in Arteries. Baltimore, Williams \& Wilkins, 1960, p. 161.

18. Schulz, H. Some remarks on the sub-microscopic anatomy and pathology of the blood-air pathway in the lung in Ciba Foundation Symposium on Pulmonary Structure and Function, A. V. S. de Reuck and M. O'Connor, Eds. Boston, Little, Brown, 1962, p. 205.

19. Othmer, D. F., and M. S. Thaker. Correlating diffusing coefficients in liquids. Industr. Engineer. Chem. 1953, 45, 589.

20. Orcutt, F. S., and M. H. Seevers. The solubility coefficients of cyclopropane for water, oils and human blood. J. Pharmacol. exp. Ther. 1937, 59, 206.

21. Gasteazoro, G., T. Hirose, J. Stopak, J. Casale, and A. I. Schaffer. False positive hydrogen test with platinum electrode in pulmonary wedge position. Amer. J. Cardiol. 1963, 12, 240.

22. Jamison, A. G. Diffusion of gases from alveolus to precapillary arteries. Science 1963, 139, 826.

23. Sobel, B. J., G. Bottex, C. Emirgil, and H. Gissen. Gaseous diffusion from alveoli to pulmonary vessels of considerable size. Circulat. Res. 1963, 13, 71.

24. Shaw, D. B. Reflux of blood in the pulmonary trunk and major pulmonary arteries during diastole. Fed. Proc. 1963, 22, 454. 